\title{
The analysis of Taiwan emergency physician's core competencies base on the ACGME idea
}

\section{Kuo-Fang Hsu}

Fu Jen Catholic University

Ping-Lung Huang ( $\nabla$ ray499@gmail.com )

Fu Jen Catholic University

\section{Tian-Shyug Lee}

Fu Jen Catholic University

Bruce C.Y. Lee

Fu Jen Catholic University

\section{Research Article}

Keywords: ACGME, Fuzzy AHP, DEMANTEL, Core Competence, Emergency physicians

Posted Date: March 16th, 2021

DOl: https://doi.org/10.21203/rs.3.rs-272427/v1

License: (9) This work is licensed under a Creative Commons Attribution 4.0 International License. Read Full License 


\title{
The analysis of Taiwan emergency physician's core competencies base on the ACGME idea
}

\author{
Kuo-Fang Hsu \\ Ph. D Candidate \& Emergency Physicians, Graduate Institute of \\ Business Administration, Fu Jen Catholic University. \\ E-Mail: kfhsums18@gmail.com \\ Phone: 886-2-29313847
}

\author{
Ping-Lung Huang* \\ Ph. D, Graduate Institute of Business Administration \\ $\mathrm{Fu}$ Jen Catholic University \\ E-Mail: ray499@gmail.com \\ Phone: 886-2-29313847 \\ ORCID http://orcid.org/0000-0002-8143-3718
}

Tian-Shyug Lee

Professor, Graduate Institute of Business Administration

Fu Jen Catholic University

E-Mail: 036665@mail.fju.edu.tw

Phone: 886-2-29313847

\author{
Bruce C.Y. Lee \\ Professor, Department of Finance and International Business \\ $\mathrm{Fu}$ Jen Catholic University \\ E-Mail: 058038@mail.fju.edu.tw \\ Phone: 886-2-29052025 \\ Fax: 886-2-29019779
}




\begin{abstract}
The development of the core competence of physicians is related to the practice of medical quality. As the most important field for cultivating the core competence of physicians, how to achieve the construction and evaluation of core competence is an important issue for medical education and management.

This study uses the large core competence framework proposed by the ACGME (Accreditation Council for Graduate Medical Education), and use Fuzzy AHP (FAHP) and DEMANTEL method to analyze the weight and priority, and the cause and effect cluster.

Study result shows that the FAHP's importance factor ranking is (1).patient care (C1) (27.83\%), (2).medical knowledge (C2) (20.77\%), (3).professionalism (C5) (17.93\%), (4). Interpersonal and communication skills (C4) (17.41\%), (5). practice-based learning and improvement (C3) (15.52\%), and (6). systems-based practice (C6) (8.233\%). In terms of DEMANTEL, the effect cluster include Patient Care (C1), Professionalism (C5) and Systems-based practice (C6), and the cause cluster includes Medical Knowledge (C2), Practice-based learning and improvement (C3) and Interpersonal and Communication skills (C4).

According to finding, the patient care $(\mathrm{C} 1)$ is the result of attitude, patience, and other five ACGME Core Competence Items. Therefore, the development of emergency physicians' also needs humanities and ethics training and practice to follows the practice-based learning (C3).

This study demonstrates to show on importance factor in emergency physician's core competencies cultivate. Furthermore, the current findings can serve as a reference for future research in the other specialists physicians cultivate.
\end{abstract}

\title{
Keywords: ACGME, Fuzzy AHP, DEMANTEL, Core Competence, Emergency physicians
}

\section{Introduction}

In the past, the literature discusses the core competences that physicians should possess. Most of them are based on the core competences that physicians should have in the United States Medical Education Evaluation Board (ACGME). They propose effective and useful methods for assessing core competences, and can improve the core competence. Competent 
education and training methods (Leach, 2002; Freyet al., 2003; Ogrinc et al., 2003; Johnson et al., 2004; Joyner, 2004). Frey et al. (2003) pointed out that the core competence proposed by ACGME is to confirm whether residents have the core competence. Massagli \& Carline (2007) questionnaire study found that senior residents had higher grades than less resident residents. Second, their factor analysis results also indicate that ACGME's large core capabilities can effectively assess the capabilities of residents.

Powers, J., (2013) points that assessment of electronic portfolios for ACGME Core Competencies may have to await more robust vocabulary to create concept identifiers capable of responding to issues of context for competencies such as ACGME Core Competencies reflecting sociologic and anthropologic content.

The development of physician's core competencies is related to the medical quality learning. The hospital is the most important place to cultivate the core competence of the physician. It has the training plan, the learning environment of the organization, whether it can inherit and develop the core competence of the physician and further validate it, is an important subject of medical management and medical education. In this study, the six core competency frameworks presented by the ACGME (Accreditation Council for Graduate Medical Education) were used to inquire and investigate the findings of the emergency physicians and try to identify possible priorities and interdependent relationships and dependency.

\section{Literature review}

This study attempts to collect relevant literature on the core competencies of the emergency department and the large core competencies of the ACGM (Accreditation Council for Graduate Medical Education).

\subsection{Core Competence:}

The ACGME (Accreditation Council for Graduate Medical Education) takes the American Board of Internal Medicine (ABIM) as a case, and evaluates the results of the Residents' Training Program (Outcome project). A competent physician should have six core competencies (Kissela et al., 2006).

In the past, the literature has discussed the core competences that physicians should possess. Most of them are based on the core competences that physicians should have in the United States Medical Education Evaluation Board (ACGME). They propose effective and 
useful methods for assessing core competences, and can improve the core competence (Leach, 2002; Freyet al., 2003; Ogrinc et al., 2003; Johnson et al., 2004; Joyner, 2004). (Frey et al., 2003) study shown on, the relevant literature discussed the focus on "The Education and Training Methods to Enhance Core Competence", and mentions that providing good clinical experience and mixing practical operations in different fields to improve the core competence that residents physicians should have it.

Frey et al. (2003) pointed out that the core competence proposed by ACGME is to confirm whether residents have the core competence. Massagli \& Carline (2007) questionnaire study found that senior residents had higher grades than less resident residents. Second, their factor analysis results also indicate that ACGME's large core capabilities can effectively assess the capabilities of residents.

Powers, J., (2013) points that assessment of electronic portfolios for ACGME Core Competencies may have to await more robust vocabulary to create concept identifiers capable of responding to issues of context for competencies such as ACGME Core Competencies reflecting sociologic and anthropologic content.

\subsection{ACGME (Accreditation Council for Graduate Medical Education)}

In the year of 1991, the Physician's core competence established by the American Medical Education Committee (ACGME, Accreditation Council for Graduate Medical Education) : 1. Patient care, 2. Medical knowledge, 3.Practice-based learning and improvement, 4. Interpersonal and communication skills, 5. Professionalism, 6. Systems-based practice. The six Core Competencies contents are as follows (Show on Table 1):

Table 1: ACGME (Accreditation Council for Graduate Medical Education)

\begin{tabular}{|c|c|c|}
\hline Code & Core Competence Items & Contents \\
\hline C1 & Patient Care & $\begin{array}{l}\text { Show concern and respect when interacting with } \\
\text { patients and family members; } \\
\text { - Collect necessary and accurate information } \\
\text { during interviews with patients; } \\
\text { - Can make informed decisions about diagnosis and } \\
\text { treatment based on patient information and their } \\
\text { wishes, the latest scientific evidence, and clinical } \\
\text { judgment } \\
\text { - Formulate and implement patient treatment plans; } \\
\text { - Consultation and health education for patients and } \\
\text { their families; } \\
\text { - Decision-making and health education using } \\
\text { information technology and supporting patient } \\
\text { care }\end{array}$ \\
\hline
\end{tabular}




\begin{tabular}{|c|c|c|}
\hline & & $\begin{array}{l}\text { Fully capable of performing medical and invasive } \\
\text { procedures required for practice } \\
\text { - Prevention of disease or the provision of relevant } \\
\text { medical care; } \\
\text { - Share work with other medical professionals to } \\
\text { provide patient-centric medical care. }\end{array}$ \\
\hline $\mathrm{C} 2$ & Medical Knowledge & $\begin{array}{l}\text { Show concern and respect when interacting with } \\
\text { patients and family members; } \\
\text { - Collect necessary and accurate information } \\
\text { during interviews with patients; } \\
\text { - Can make informed decisions about diagnosis and } \\
\text { treatment based on patient information and their } \\
\text { wishes, the latest scientific evidence, and clinical } \\
\text { judgment }\end{array}$ \\
\hline $\mathrm{C} 3$ & $\begin{array}{l}\text { Practice-based learning } \\
\text { and improvement) }\end{array}$ & $\begin{array}{l}\text { - Self-reflective assessment learning; } \\
\text { - Self-directive learning; } \\
\text { - Lifelong Learning }\end{array}$ \\
\hline $\mathrm{C} 4$ & $\begin{array}{l}\text { Interpersonal and } \\
\text { communication skills }\end{array}$ & $\begin{array}{l}\text { Establish and maintain appropriate medical and } \\
\text { ethical relationships with patients; } \\
\text { - Use effective listening skills and use effective } \\
\text { non-spoken, narrative, questioning, and writing } \\
\text { skills to elicit and provide information; } \\
\text { - Work effectively with members of the same and } \\
\text { cross-cutting medical team. }\end{array}$ \\
\hline $\mathrm{C} 5$ & Professionalism & $\begin{array}{l}\text { Altruism and respect for others; } \\
\text { - Medical behaviors consistent with medical ethical } \\
\text { principles; } \\
\text { - Can be sensitive to differences in other people's } \\
\text { culture, age, gender, and disability }\end{array}$ \\
\hline C6 & Systems-based practice & $\begin{array}{l}\text { Understand how your own medical care for } \\
\text { patient care and other medical personnel affects } \\
\text { other medical personnel, medical institutions and } \\
\text { the social environment, and how each element of } \\
\text { these systems affects your own medical } \\
\text { operations; } \\
\text { - Know the differences between the models of } \\
\text { medical operations and care systems, including } \\
\text { methods of cost control and resource allocation; } \\
\text { - Implement cost-effective medical care and } \\
\text { resource allocation without compromising quality } \\
\text { of care; } \\
\text { - Promote quality patient care and help patients } \\
\text { deal with the complexities of the system; } \\
\text { Know how to work with health care managers } \\
\text { and health care providers to evaluate, coordinate, } \\
\text { and improve health care, and understand how } \\
\text { these activities can affect system performance. }\end{array}$ \\
\hline
\end{tabular}

Data source\#: ACGME (Accreditation Council for Graduate Medical Education) 


\section{Methodology}

\subsection{Methodology choice}

This study serves as evaluating the relative importance of core competencies to the emergency physicians in Taiwan. Two multi-criteria decision-making methodologies said Fuzzy AHP (FAHP) and DEMATEL, using expert opinion input, are used for the relative importance of practices determination.

\subsection{Fuzzy AHP method}

\subsubsection{Questionnaire design}

This study uses ACGME six core competence items as Fuzzy AHP (Saaty, 1980 ; Herrera et al., 2004) evaluation criteria and symbols (Show on Figure 1) as follows: Patient Care (C1), Medical Knowledge (C2), Practice-based learning and improvement (C3), Interpersonal and communication skills (C4), Professionalism (C5), and Systems-based practice (C6). (Shown on Appendix I)

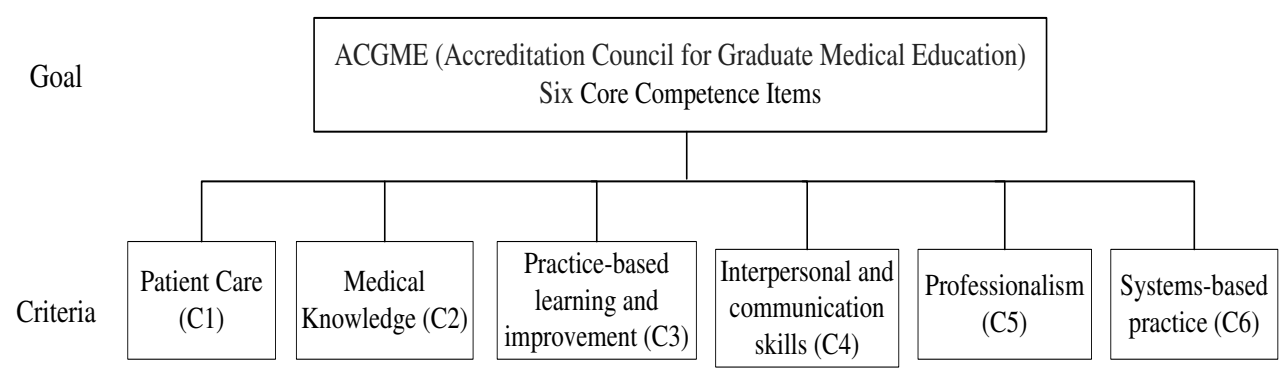

Figure 1. Hierarchy model of the relative importance of factors

\subsubsection{FAHP calculation formula process}

In this section, we briefly review the concepts of fuzzy hierarchical evaluation. The subsequent sections detail the computational processes of the FAHP.

The FAHP is based on fuzzy interval arithmetic with TFNs (Triangular Fuzzy Numbers) (Figure 2 and Table 2) and a confidence index with an interval mean approach to determine the weights for evaluative elements; therefore, this method is suitable for analyzing small samples of questionnaire feedback provided by Taiwan emergency physicians' expert. 


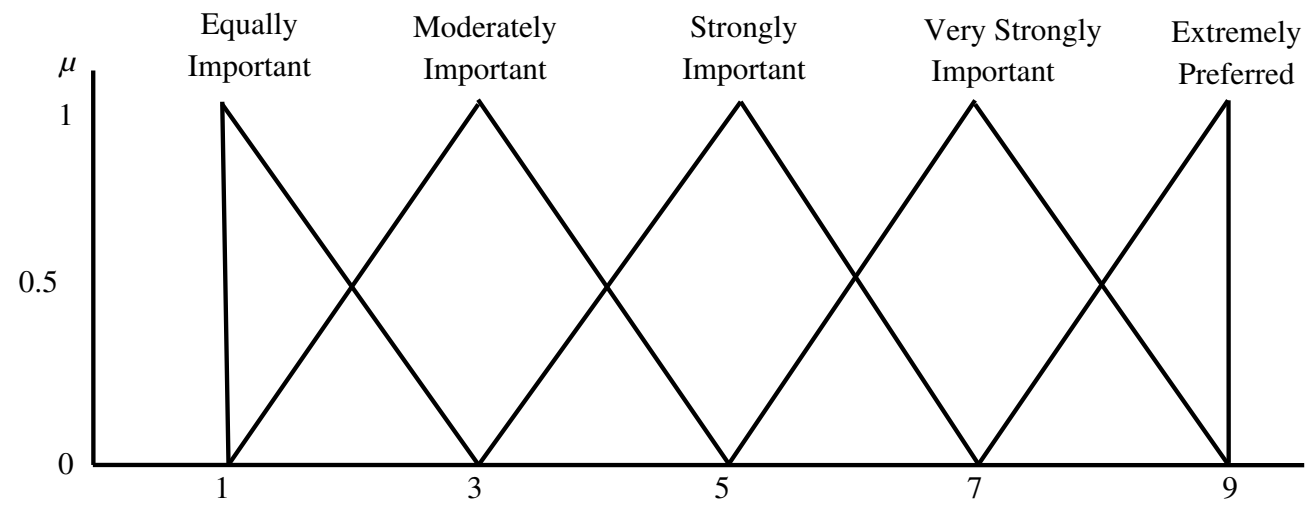

Figure 2: Linguistic variables for the importance weight of each criterion (Chang, 1996)

Table 2: Fuzzy Linguistic Scale of Fuzzy Numbers (example) (Gumus, 2009)

\begin{tabular}{ccc}
\hline Fuzzy number & Linguistic & Scale of fuzzy number \\
\hline 9 & Perfect & $(8,9,10)$ \\
8 & Absolute & $(7,8,9)$ \\
7 & Very good & $(6,7,8)$ \\
6 & Fairly good & $(5,6,7)$ \\
5 & Good & $(4,5,6)$ \\
4 & Preferable & $(3,4,5)$ \\
3 & Not bad & $(2,3,4)$ \\
2 & Weak advantage & $(1,2,3)$ \\
1 & Equal & $(1,1,1)$ \\
\hline
\end{tabular}

The procedures involved in executing the FAHP method are outlined as follows.

Step 1: Construct pairwise comparison matrices among all the criteria in the dimensions of the hierarchical system. Assign linguistic terms to the pairwise comparisons by determining which is the more important of every two dimensions, as indicated in the following matrix $\widetilde{A}$ (shown in equation (1)):

$$
\widetilde{\boldsymbol{A}}=\left[\begin{array}{cccc}
1 & \tilde{\mathfrak{a}}_{12} & \cdots & \tilde{\mathfrak{a}}_{1 \mathfrak{n}} \\
\tilde{\mathfrak{a}}_{21} & 1 & \cdots & \tilde{\mathfrak{a}}_{2 \mathfrak{n}} \\
\vdots & \vdots & \ddots & \vdots \\
\tilde{\mathfrak{a}}_{\mathrm{n} 1} & \tilde{\mathfrak{a}}_{\mathfrak{n} 2} & \cdots & 1
\end{array}\right]=\left[\begin{array}{cccc}
1 & \tilde{\mathfrak{a}}_{12} & \cdots & \tilde{\mathfrak{a}}_{1 \mathfrak{n}} \\
1 / \tilde{\mathfrak{a}}_{12} & 1 & \cdots & \tilde{\mathfrak{a}}_{2 \mathfrak{n}} \\
\vdots & \vdots & \ddots & \vdots \\
1 / \tilde{\mathfrak{a}}_{1 \mathrm{n}} & 1 / \tilde{\mathfrak{a}}_{1 \mathrm{n}} & \cdots & 1
\end{array}\right] \cdots(1)
$$

Where

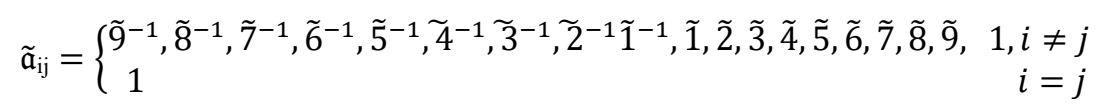

Step 2: Apply the geometric mean technique to define the fuzzy geometric mean and fuzzy weights of each criterion, as demonstrated by Hsieh et al. (2004) (shown in equation (2)): 


$$
\begin{aligned}
& \tilde{\gamma}_{i}=\left(\widetilde{\alpha}_{i 1} \otimes \cdots \otimes \widetilde{\alpha}_{i j} \otimes \cdots \otimes \widetilde{\alpha}_{i n}\right)^{1 / n} \\
& \widetilde{w}_{i}=\tilde{\gamma}_{i} \otimes\left[\tilde{\gamma}_{1} \otimes \cdots \otimes \tilde{\gamma}_{i} \otimes \cdots \otimes \tilde{\gamma}_{n}\right]^{-1}
\end{aligned}
$$

In this equation (2), $\widetilde{\alpha}_{\mathrm{ij}}$ is the fuzzy comparison value of dimension $i$ with criterion $j$; thus, $\tilde{\gamma}_{i}$ is the geometric mean of the fuzzy comparison values of criterion $i$ with each other criterion. In addition, $w_{i}$ is the fuzzy weight of the $i$ th criterion, and it can be indicated by a TFN; $w_{i}=\left(l w_{i}, m w_{i}, u w_{i}\right)$, where $l w_{i}, m w_{i}$, and $u w_{i}$ represent the lower, middle, and upper values of the fuzzy weight of the $i$ th dimension, respectively (Sun, 2010).

The FAHP framework is constructed in the form of a matrix, and a local priority vector can be derived as an estimate of relative importance associated with the components being compared by solving the equation (3):

$$
A \bar{w}=\lambda_{\max } \bar{w}
$$

where $A$ is the matrix of the pair-wise comparison, $\bar{w}$ is the eigenvector, and $\lambda_{\max }$ is the maximum eigenvalue. Saaty (1996) suggested the use of a consistency index (C.I) for executing test procedures (C.I $<0.1$, permissible errors range). A consistency ratio (C.R) can also be used for consistency determination; if C.R $<0.1$, then the consistency level of the matrix already exceeds the allowed error range and decision-makers should reconsider their decision-making relationship. The C.I and C.R are calculated using equations (4) and (5):

$$
\begin{aligned}
& \text { C.I }=\frac{\lambda_{\text {max }}-n}{n-1} \\
& \text { C.R }=\frac{\text { C.I }}{\text { R.I }}
\end{aligned}
$$

Where R.I represents the average CI obtained from numerous simulation runs, and it varies according to the matrix order (Table 2).

Table 2: Reference Values of the R.I. for Different $n$ Values

\begin{tabular}{c|cccccccccc}
$\mathrm{n}$ & 1 & 2 & 3 & 4 & 5 & 6 & 7 & 8 & 9 & 10 \\
\hline R.I. & 0 & 0 & 0.58 & 0.9 & 1.12 & 1.24 & 1.32 & 1.41 & 1.45 & 1.49
\end{tabular}

Source: Enyinda et al. (2010); Developed by Saaty

Overall hierarchy consistency can be tested according to equation (6):

$$
\text { C.R.H }=\frac{\text { C.I.H }}{\text { R.I.H }}
$$




$$
\begin{aligned}
& \text { C.I.H }=\sum_{j=1}^{n} \sum_{i=1}^{n} W_{i j} C . I_{i, j+1} \\
& \text { R.I.H }=\sum_{j=1}^{n} \sum_{i=1}^{n} W_{i j} \text { R.I } I_{i, j+1}
\end{aligned}
$$

$W_{i j}=$ the total weight of the $i$ th element of Layer $\mathrm{j}$

$C . I_{i, j+1}=$ the C.I of all elements of Layer $j+1$ against the $i$ th element of Layer $j$.

$R \cdot I_{i, j+1}=$ the R.I of all elements of Layer $j+1$ against the $i$ th element of Layer $j$.

In this equation, C.R.H represents the consistency ratio hierarchy, C.I.H represents the consistency index hierarchy, and R.I.H represents the random index hierarchy. An acceptable inconsistency limit should be 0.1 (Saaty, 1980).

\subsection{DEMATEL method}

\subsubsection{Questionnaire design}

The second questionnaire designed for DEMATEL (Tzeng et al., 2007). This questionnaire designed for pairwise comparison to evaluate the influence of each score, where scores of $0,1,2$, and 3 represent: (no influence), (low influence), (high influence), and (very high influence), respectively (Tamura and Akazawa, 2005). (Show on Table 3)

\begin{tabular}{|c|c|c|c|c|c|c|c|}
\hline & Code & $\mathrm{C} 1$ & $\mathrm{C} 2$ & $\mathrm{C} 3$ & $\mathrm{C} 4$ & C5 & C6 \\
\hline Code & Question & 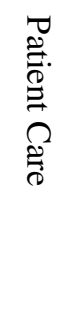 & 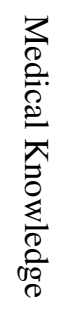 & 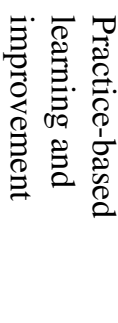 & 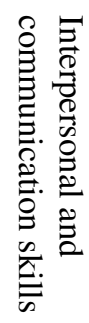 & 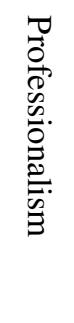 & 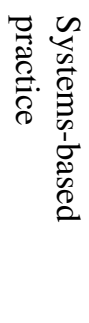 \\
\hline $\mathrm{C} 1$ & Patient Care & N/A & & & & & \\
\hline $\mathrm{C} 2$ & Medical Knowledge & & N/A & & & & \\
\hline $\mathrm{C} 3$ & $\begin{array}{l}\text { Practice-based learning } \\
\text { and improvement }\end{array}$ & & & N/A & & & \\
\hline $\mathrm{C} 4$ & $\begin{array}{l}\text { Interpersonal and } \\
\text { communication skills }\end{array}$ & & & & N/A & & \\
\hline $\mathrm{C} 5$ & Professionalism & & & & & N/A & \\
\hline C6 & Systems-based practice & & & & & & N/A \\
\hline
\end{tabular}

Table 3 The DEMATEL questionnaire of Taiwan emergency physicians' core competencies

Score: 0 : no influence, 1: low influence 2: high influence 3: very high influence

\subsubsection{Analyses process :}

Step 1: acquire and compute the average initial matrix 
Suppose $\mathrm{L}$ experts and $\mathrm{n}$ factors are considered in a study. A pair-wise comparison with respect to the influence of factor $\mathrm{i}$ on factor $\mathrm{j}$ is determined $\left(f_{i j}\right)$ and is quantified using a 4-point (0-3) measurement scale. See 3.3.1 for the linguistic assignments of each level of the scale. Each expert will be asked to provide a completed $\mathrm{n} \times \mathrm{n}$ non-negative response matrix $u^{x}=\left[u_{i j}^{x}\right]$, with $1 \leq \mathrm{x} \leq L$. Where $u^{1}, u^{2}, \ldots u^{L}$ represents each of the $L$ experts response matrices, $u_{y}^{x}$ is an integer (scale measure) representing each element of $u_{x}$ and diagonal elements of each response matrix $u_{x}$ set to zero.

An averaged $\mathrm{n} \times \mathrm{n}$ matrix $A$ using all the experts' comparisons is determined by averaging the L experts' scores using expression (1):

$$
A=\left(f_{i j}\right)=\frac{1}{L} \sum_{x=1}^{L}\left[u_{i j}^{x}\right]
$$

Step 2: compute the normalized initial direct-relation matrix $D$

There is normalized the direct relation matrix, that is multiply the elements of the entire matrix $A$ by $S$,

$$
\text { Let } S=\frac{1}{\operatorname{MAX}_{1 \leq i \leq n} \sum_{i=1}^{n} X i j}
$$

Then, it can be get a normalized initial direct-relation matrix $D$,

$$
D=A \times S=\frac{X}{\operatorname{MAX}_{1 \leq i \leq n} \sum_{i=1}^{n} X i j}
$$

Step 3: compute the total relation matrix $T$

Where $\quad T=\frac{D}{I-D}$

and $I$ is unit matrix,

through the formula : Matrix $T=$ Matrix $D+$ Matrix $I D$ (in-direct-relation matrix)

and $T=D+I D=\sum_{i=1}^{\infty} D^{i}=D+D^{2}+D^{3}+\cdots \ldots+D^{\infty}$

$D \times T=D^{2}+D^{3}+\cdots+D^{\infty}$

and equations $(11)-(12)$, get $(I-D) \times D=\mathrm{D}-D^{\infty+1}, D^{\infty+1} \approx 0$

then $T=\frac{D}{I-D}, T=\left[t_{i j}\right]_{n \times n}, i, j=1,2 \ldots \ldots, n$

Step 4 Drawing the Causal diagram

The $D x$ and $R \mathrm{x}$ are respectively the sums of rows, and columns from the total-relation matrix $T$, then calculate the degree of effect $(D+R)$ and the degree of cause (D-R), where 
$(D+R)$ represents the strength of the relationship between the criteria, and (D-R) represents the strength of the criterion's influence or impact.

There are (D+R) and (D-R) values of each criterion are plotted on the graph, with $(D+R)$ as the horizontal axis; (D-R) as the vertical axis. (Show on Figure 3)

\subsection{Research object}

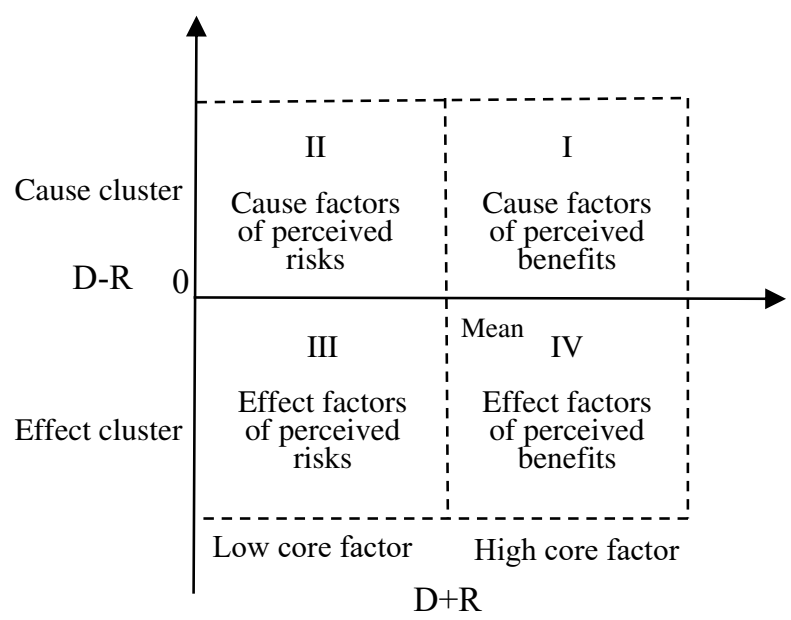

Figure $3:$ Causal diagram

This study is based on the architecture of a physician's core competence established by the ACGME (Accritation Council for Graduate Medical Education) (Show on Figure 1)

\subsection{Sampling}

In this study, we collected in the Taiwan teaching hospital with teaching duty of the attending physician (Visiting Staff) above the emergency physicians by the questionnaire objective.

\subsection{Ethic requirement}

This is study are use FAHP and DEMATEL questionnaire to inquire the physician (Visiting Staff) above the emergency physicians opinion, and we don't use medical record, therefore we don't need to approval with the ethics committee.

This study all of methods were carried out in accordance with relevant guidelines and regulations.

This questionnaire is emergency physicians reply after filling out, so they know and are willing to reply. 


\section{Results}

In this study, we totally collective 21 Taiwan emergency physicians questionnaire, and the descriptive statistics are as follows: (Show on Table 4).

Table 4. The demographic variables of 21 experts

\begin{tabular}{|c|c|c|}
\hline Demographic variables & Number $(\mathrm{N}=21)$ & Percentage \\
\hline \multicolumn{3}{|l|}{ Level } \\
\hline Superintendent & 0 & $0 \%$ \\
\hline Assistant administrator & 6 & $28.57 \%$ \\
\hline Director & 10 & $47.62 \%$ \\
\hline Visiting Staff & 5 & $23.81 \%$ \\
\hline Resident & 0 & $0 \%$ \\
\hline \multicolumn{3}{|l|}{ The career length field } \\
\hline$>21$ years & 8 & $38.10 \%$ \\
\hline$>16$ and $<20$ years & 7 & $33.33 \%$ \\
\hline$>11$ and $<15$ years & 4 & $19.05 \%$ \\
\hline$>6$ and $<10$ years & 2 & $9.52 \%$ \\
\hline
\end{tabular}

\subsection{Fuzzy AHP analysis result}

As follows 3.2.2 calculation formula process, we found that $\mathrm{CI}=0.09591(<0.1), \mathrm{CR}=$ $0.0773(<0.1)$, and eigenvector $(\lambda \max )=6.48$; this result is acceptable (Appendix II). The weights and rankings are $\mathrm{C} 1: 27.8 \%, \mathrm{C} 2: 20.8 \%, \mathrm{C} 3: 15.5 \% . \mathrm{C} 4: 17 \%, \mathrm{C} 5: 17.9 \%$ and $\mathrm{C} 6: 8.2 \%$.

\subsubsection{Fuzzy AHP Overall object and criteria weights and ranking analysis results}

Based on empirical analysis of the Fuzzy AHP questionnaire results (Table 5), We found that the first-ranked importance factor is $\mathrm{C} 1$ patient care $(27.83 \%)$, the second-ranked is medical knowledge (C2) (20.77\%), the third-ranked is professional literacy (C5) (17.93\%), fourth-ranked is Interpersonal and communication skills (C4) (17.41\%), fifth-ranked is Practice-based learning and improvement (C3) (15.52\%), and sixth-ranked is systems-based practice (C6) (8.233\%).

Table 5: Overall object and criteria weights and ranking 


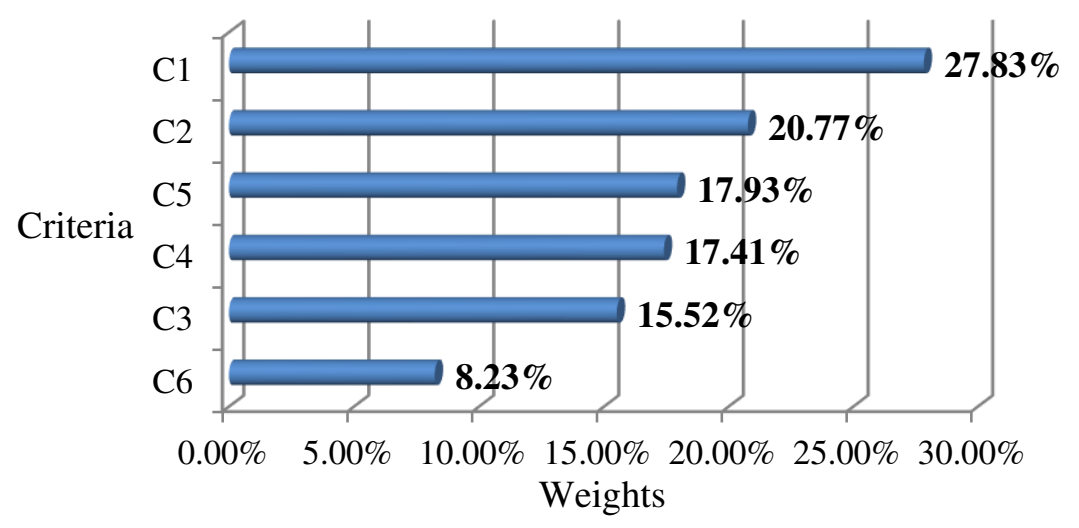

\subsection{DEMANTEL analysis results}

\subsubsection{DEMANTEL analysis process}

As follows 3.3.2 analyses process and found result below:

Step 1: Acquire and compute the average initial matrix $A$ by 21 Taiwan emergency physicians questionnaire. The resulted show on table 6 .

Table 6 Overall average expert opinion matrix (matrix $A$ )

\begin{tabular}{|c|c|c|c|c|c|c|c|c|c|}
\hline$A=$ & $\mathrm{C} 1$ & $\mathrm{C} 2$ & $\mathrm{C} 3$ & $\mathrm{C} 4$ & $\mathrm{C} 5$ & C6 & & & \\
\hline $\mathrm{C} 1$ & 0 & \begin{tabular}{|l|}
1.909091 \\
\end{tabular} & 1.727273 & 2.090909 & 2.181818 & 2.090909 & & 10 & \\
\hline $\mathrm{C} 2$ & 2.545455 & 0 & 1 & 1.454545 & 1.272727 & 1.272727 & & \begin{tabular}{|l|}
7.545455 \\
\end{tabular} & $\operatorname{Max}$ \\
\hline $\mathrm{C} 3$ & 2 & 1.454545 & 0 & 1.090909 & 1.636364 & 1.454545 & $\mathrm{~S}$ & 7.636364 & 10 \\
\hline $\mathrm{C} 4$ & 2.090909 & 1.090909 & 1.454545 & 0 & 1.545455 & 1.363636 & & \begin{tabular}{|l|}
7.545455 \\
\end{tabular} & \\
\hline $\mathrm{C} 5$ & 2.272727 & 1.363636 & 1.181818 & 1.636364 & 0 & 1.636364 & & 8.090909 & \\
\hline C6 & 2.090909 & 1.636364 & 1.363636 & 1.090909 & 1.454545 & 0 & & 7.636364 & \\
\hline
\end{tabular}

Step 2: Compute the normalized initial direct-relation matrix $D$, show on table 7.

Table 7 Normalized direct relation matrix (matrix $D$ )

\begin{tabular}{c|c|c|c|c|c|c}
\hline $\mathrm{D}=\mathrm{A} \times \mathrm{S}$ & $\mathrm{C} 1$ & $\mathrm{C} 2$ & $\mathrm{C} 3$ & $\mathrm{C} 4$ & $\mathrm{C} 5$ & $\mathrm{C} 6$ \\
\hline $\mathrm{C} 1$ & 0 & 0.190909 & 0.172727 & 0.209091 & 0.218182 & 0.209091 \\
\hline $\mathrm{C} 2$ & 0.254545 & 0 & 0.1 & 0.145455 & 0.127273 & 0.127273 \\
\hline $\mathrm{C} 3$ & 0.2 & 0.145455 & 0 & 0.109091 & 0.163636 & 0.145455 \\
\hline $\mathrm{C} 4$ & 0.209091 & 0.109091 & 0.145455 & 0 & 0.154545 & 0.136364 \\
\hline $\mathrm{C} 5$ & 0.227273 & 0.136364 & 0.118182 & 0.163636 & 0 & 0.163636 \\
\hline $\mathrm{C} 6$ & 0.209091 & 0.163636 & 0.136364 & 0.109091 & 0.145455 & 0 \\
\hline
\end{tabular}

Step 3: Compute the total relation matrix $T$, show on table 8 .

Table 8: Total impact matrix (matrix $T$ )

\begin{tabular}{c|c|c|c|c|c|c|c}
\hline $\mathrm{T}=$ & $\mathrm{C} 1$ & $\mathrm{C} 2$ & $\mathrm{C} 3$ & $\mathrm{C} 4$ & $\mathrm{C} 5$ & $\mathrm{C} 6$ & $\mathrm{Rx}$ \\
\hline $\mathrm{C} 1$ & 0.956864 & 0.856995 & 0.783282 & 0.869952 & 0.929987 & 0.902976 & 5.3000562 \\
\hline $\mathrm{C} 2$ & 0.974029 & 0.56265 & 0.605961 & 0.691481 & 0.719637 & 0.702735 & 4.2564929 \\
\hline
\end{tabular}




\begin{tabular}{c|c|c|c|c|c|c|c}
\hline C3 & 0.934853 & 0.689121 & 0.512067 & 0.660618 & 0.74522 & 0.715142 & 4.2570207 \\
\hline C4 & 0.933725 & 0.6559 & 0.636068 & 0.556944 & 0.734258 & 0.703693 & 4.2205888 \\
\hline C5 & 0.995087 & 0.711824 & 0.646952 & 0.73312 & 0.637517 & 0.76069 & 4.4851882 \\
\hline C6 & 0.94263 & 0.703958 & 0.632617 & 0.661619 & 0.732116 & 0.588729 & 4.2616686 \\
\hline Dx & 5.737189 & 4.180448 & 3.816948 & 4.173733 & 4.498734 & 4.373964 & 0.7439171 \\
\hline
\end{tabular}

Step 4: Drawing the Causal diagram

1. Analyzing the degree of central role and relation:

As get the analyzed result the matrix $T$ (Show on table 8), then, we can calculate the degree of central role $(D x+R x)$ and $(D x-R x)$ values.

The degree of central role $(\mathrm{Dx}+\mathrm{Rx})$ and $(\mathrm{Dx}-\mathrm{Rx})$ in DEMATEL represents the strength of influences both dispatched and received. On the other hand, if the (Dx - Rx) is positive, then the evaluation criterion $\mathrm{x}$ dispatches the influence to other evaluation criteria more than it receives. If the $(\mathrm{Dx}-\mathrm{Rx})$ is negative, the evaluation criterion $\mathrm{x}$ receives the influence from other evaluation criteria more than it dispatched. The (Dx - Rx) values are reported in Table 9.

Table 9: The degree of central role $(D+R$ and $D-R)$ sheet

\begin{tabular}{c|c|c|c|c|c|c}
\multicolumn{2}{c}{$\mathrm{C} 1$} & $\mathrm{C} 2$ & $\mathrm{C} 3$ & $\mathrm{C} 4$ & $\mathrm{C} 5$ & $\mathrm{C} 6$ \\
\hline $\mathrm{D}+\mathrm{R}$ & 11.03724 & 8.436941 & 8.073968 & 8.394322 & 8.983922 & 8.635632 \\
\hline $\mathrm{D}-\mathrm{R}$ & -0.437133 & 0.076045 & 0.440073 & 0.046856 & -0.013546 & -0.112295 \\
\hline
\end{tabular}

2. Drawing causal diagram

The graphical representation (the prominence-causal diagram) and digraphical relationships are now constructed. This step will allow a clearer visualization of the structure and relationships amongst the emergency physicians' core competencies criteria. One of the first activities of this sub-step is to plot the various emergency physicians' core competencies criteria on a two-axes the prominence horizontal axis $(R+D)$ and the net cause/effect vertical axis $(R-D)$ (Show on Figure 4). There are can help us observe general patterns and relationships amongst all the programs simultaneously and in pairs. For example, we can see that C3 have very stronger influence/effect on the other programs, and is more of an effect or influenced by others.

The development of the digraphs in Figure 4 shows the interrelationships amongst each of the individual core competencies selection criteria. We can also observe general clusters into cause and effect groups. Generally the core competencies selection criteria that are part of the effect cluster include C1, C5 and C6; the cause cluster includes C2, 
$\mathrm{C} 3$ and $\mathrm{C} 4$. The causal relationships among core competencies selection criteria can be depicted as the causal diagram (Show on Figure 4).this figure is shown that Practicebased learning and improvement (C3) is the most influence and the strongest connection to other criteria.

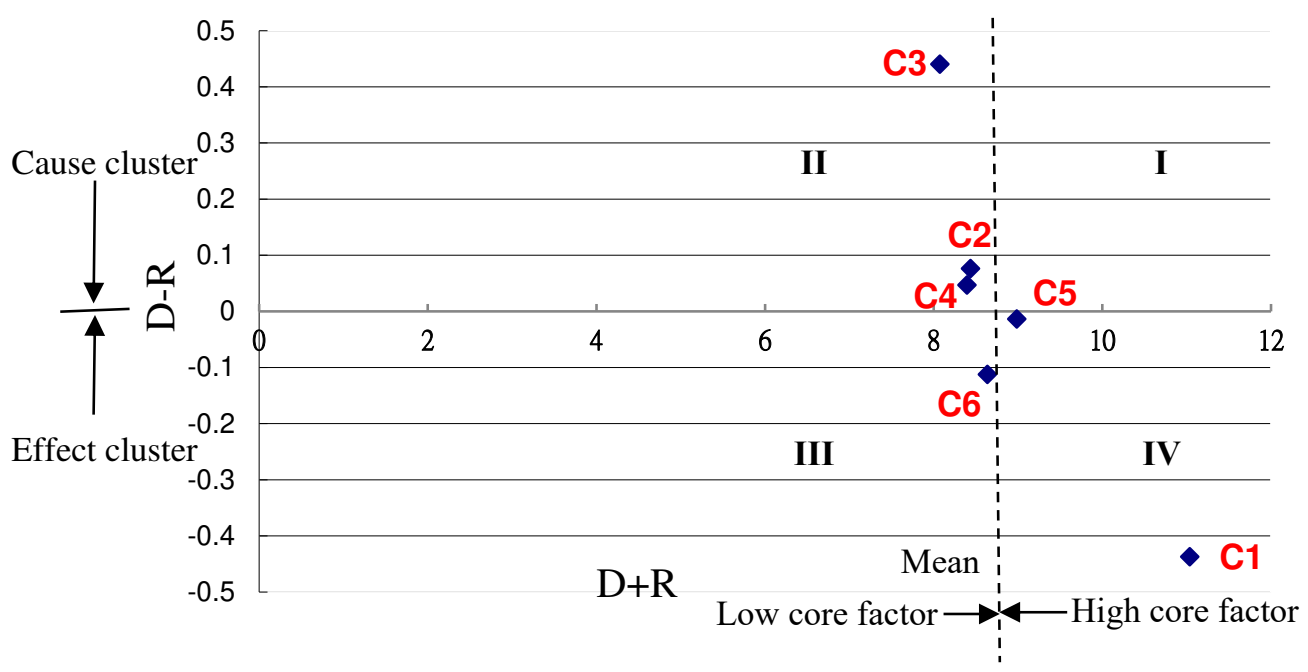

Using $\bullet$ symbol for evaluating criteria: Patient Care (C1), Medical Knowledge (C2), Practice-based learning and improvement (C3), Interpersonal and communication skills (C4), Professionalism (C5), and Systems-based practice (C6)

Figure 4: Causal diagram

\section{Conclusion and Discussion}

This study uses the fuzzy AHP and DEMATEL methods to analyze the relative importance factors of Taiwan emergency physicians' core competencies. The results of this study may hopefully help the emergency physicians that core competencies are crucial factors found in this study. From the fuzzy AHP results, we can understand that first-ranked important is Patient Care (C1) (27.83\%). Moreover, the second-ranked important is Medical Knowledge (C2) $(20.77 \%)$, and the third-ranked important is Professionalism (C5) (17.93\%). Therefore, the medical education managers should be pay special attention to Patient Care.

The development of the digraphs in Figure 4 shows the interrelationships amongst each of the individual core competence items. We can also observe general clusters into Cause and Effect Groups. Generally the core competence items that are part of the effect cluster include Patient Care (C1), Professionalism (C5) and Systems-based practice (C6); the Cause cluster includes Medical Knowledge (C2), Practice-based learning and improvement (C3) and Interpersonal and Communication skills (C4).The causal relationships among of Taiwan emergency physicians' core competencies criteria can be depicted as the causal diagram (Fig. 
4). This figure is shown that Practice-based learning and improvement (C3) is the most influence and the strongest connection to other criteria.

From the DEMATEL results, we can understand the Practice-based learning and improvement $(\mathrm{C} 3)$ is the most influence and the strongest connection to other criteria. According to DEMATEL analysis results, the Practice-based learning and improvement (C3) could directly or indirectly influence many other characteristics such as Medical Knowledge (C2) and Interpersonal and Communication skills (C4). One major limitation is the evaluation effort required with these techniques. Any combination of the ACGME five entries reflects all competencies with the exception of practice-based learning (C3). This deficit can be corrected with revision of portfolio guidelines. (Jarviset, etc., 2004). The patient care (C1) is the result of attitude, patience, and other five ACGME Core Competence Items. Therefore, the development of emergency physicians also needs humanities and ethics training and practice to follows the practice-based learning by this research finding.

In this study, we present Fuzzy AHP and DEMATEL as a generalized method to the relative importance factors of Taiwan emergency physicians' core competencies under a fuzzy environment.

\section{Limitations and Further Research}

For this study evaluators to each method (Fuzzy AHP and DEMATEL) had to each complete six comparisons (ACGME six core competencies). Fatigue is easily a possibility which may cause some confuse problems.

There are other multiple attribute decision-making methods such as Fuzzy ANP, TOPSIS and ELECTRE, which could be applied for ranking and relative the Taiwan emergency physician's criteria.

Further research, it may be the application of these methods to the other specialists physician's core competencies evaluation and the comparison of the results. 


\section{References}

ACGME Outcome Project: Accreditation Council for Graduate Medical Education Web site. Available at: HYPERLINK "http://www.acgme.org" http://www.acgme.org, 2000: Accessed June 27, 2008.

Anderson, C. I., A. B. Jentz, et al., 2005, "Assessing the competencies in general surgery residency training." American Journal of Surgery 189(3): 288-292.

Barnsley, L., Lyon, P.M., Ralston, S.J., Hibbert, E.J., Cunningham, I., Gordon, F.C., Field,M.J., 2004. Clinical skills in junior medical officers: a comparison of self-reported confidence and observed competence. Medical Education 38 (4), 358-367.

Brailovsky, C. A., \& Grand'Maison, P., 2000, "Using Evidence to Improve Evaluation: A Comprehensive Psychometric Assessment of a SP-Based OSCE Licensing Examination." Advances in Health Sciences Education 5:207-219.

Caverzagie, K. J., J. A. Shea, et al., 2008, "Resident identification of learning objectives after performing self-assessment based upon the ACGME core competencies." Journal of General Internal Medicine 23(7): 1024-1027.

Cerilli, G. J., Merrick, H. W., \& Staren, E. D. ,2001," Objective Structured Clinical Examination Technical Skill Stations Correlate More Closely with Postgraduate Year Level than Do Clinical Skill Stations. " The American Surgeon 67(4):323-327.

Chen et al., 2008, "Gender-specific response to social determinants of self-rated health: A multilevel approach. " Social Science \& Medicine.

Chang, D. Y. (1996),"Applications of the extent analysis method on fuzzy AHP," European Journal of Operational Research, 95, 649-65.

Chiu, Y. J., Chen, H. C., Tzeng, G. H., and Shyu, J. Z., 2006, "Marketing strategy based on customer behavior for the LCD-TV," International Journal of Management and Decision Making, Vol. 7, No. 2-3, 143-165.

Delzell, J. E., Jr., E. N. Ringdahl, et al.,2005, "The ACGME core competencies: a national survey of family medicine program directors." Family Medicine 37(8): 576-580.

Enyinda, C. I., Dunu, E., \& Gebremikael, F. (2010) An analysis of strategic supplier selection and evaluation in a generic pharmaceutical firm supply chain. ASBBS Annual Conference: Las Vegas, 17, 77-91. Retrieved from http://asbbs.org/files/2010/ASBBS2010v1/PDF/E/Enyinda.pdf

Frey, K., F. Edwards, et al., 2003, "The 'Collaborative Care' curriculum: an educational model addressing key ACGME core competencies in primary care residency training." Medical Education 37(9): 786-789.

Greenberg, J. A., J. L. Irani, et al., 2007, "The ACGME competencies in the operating room." Surgery 142(2): 180-184.

Gumus, A. T. (2009),"Evaluation of hazardous waste transportation firms by using a two step fuzzy-AHP and TOPSIS methodology," Expert Systems with Applications, 36, 4067-4074.

Hsieh, T. Y., Lu, S. T., \& Tzeng, G. H. (2004). Fuzzy MCDM approach for planning and design tenders selection in public office buildings, International journal of project management, 22(7), 573-584.

Herrera-Viedma, E., Herrera, F., Chiclana, F., \& Luque, M. (2004). Some issues on consistency of fuzzy preference relations, European Journal of Operational Research, 154, 98-109.

Jarvis, R. M., O'Sullivan, P. S., McClain, T., \& Clardy, J. A. (2004). Can one portfolio measure the six ACGME general competencies?. Academic Psychiatry, 28(3), 190-196. 
Johnson, C. E., L. C. Hurtubise, et al., 2004, "Learning management systems: technology to measure the medical knowledge competency of the ACGME." Medical Education 38(6): 599-608.

Joyner, B. D., 2004, "An historical review of graduate medical education and a protocol of Accreditation Council for Graduate Medical Education compliance." The Journal of Urology, 172(1): 34-39.

Kissela, B., Harris, S., Kleindorfer, D., Lindsell, C., Pascuzzi, R., Woo, D., et al., 2006, "The Use of Standardized Patients for Mock Oral Board Exams in Neurology: A Pilot Study.

" BMC Medical Education, 6, 22.

Leach, David C., 2002, "Building and Assessing Competence: The Potential for Evidencebased

Graduate Medical Education. "Quality Management in Health Care 11(1):39-44.

Lin, C.L. and Tzeng, G.H. (2009) 'A value-created system of science (technology) park by using DEMATEL', Expert Systems with Applications, Vol. 36, No. 6, pp.9683-9697.

Massagli, T. L. and J. D. Carline, 2007, "Reliability of a 360-degree evaluation to assess resident competence." American Journal of Physical Medicine \& Rehabilitation /Association of Academic Physiatrists 86(10): 845-852.

Maker, V. K. and M. B. Donnelly, 2008, "Surgical resident peer evaluations-what have we learned." Journal of Surgical Education 65(1): 8-16.

Ogrinc, G., L. A. Headrick, et al., 2003, "A framework for teaching medical students and residents about practice-based learning and improvement, synthesized from literature review." Academic Medicine: Journal Of The Association Of American Medical Colleges, 78(7): 748-756.

Powers, J., Spickard, A., DeRiemer, S. \& Denny, J. (2013) “Analysis of pre-clinical student narratives- progress in assessment of ACGME competencies." Journal of Contemporary Medical Education, 1 (1), 62-65. doi:10.5455/jcme.20121203031836

Saaty, T. L. (1980). The Analytic Hierarchy Process. New York: McGraw Hill Publications.

Saaty, T. L. (1996), Decision Making with Dependence and Feedback: The Analytic Network Process, Pittsburgh: RWS Publications.

Sun, C. C. (2010), "A performance evaluation model by integrating fuzzy AHP and fuzzy TOPSIS methods," Expert systems with applications, 37, 7745-7754.

Tamura, H., Akazawa, K.(2005).Structural modeling and systems analysis of uneasy factors for realizing safe, secure and reliable society. Journal of Telecommunications and Information Technolegy,3,64-72. 
Figures

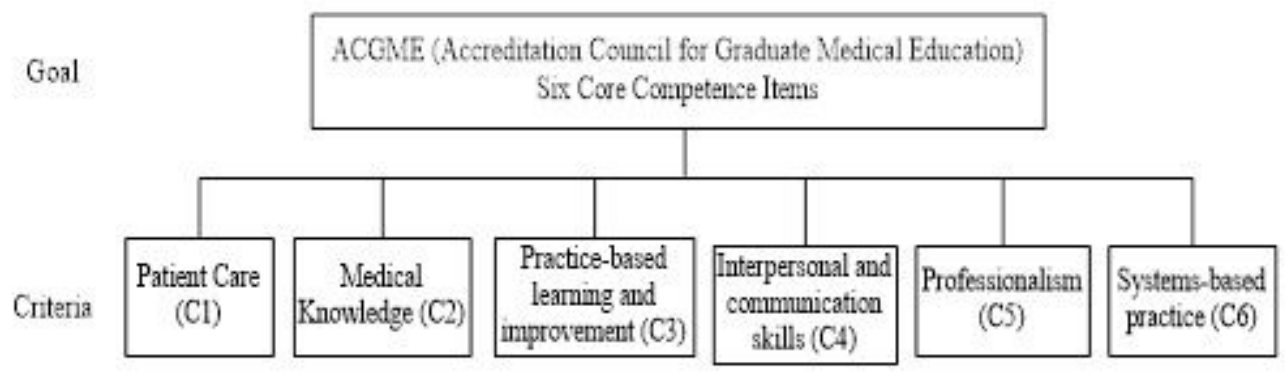

Figure 1

Hierarchy model of the relative importance of factors

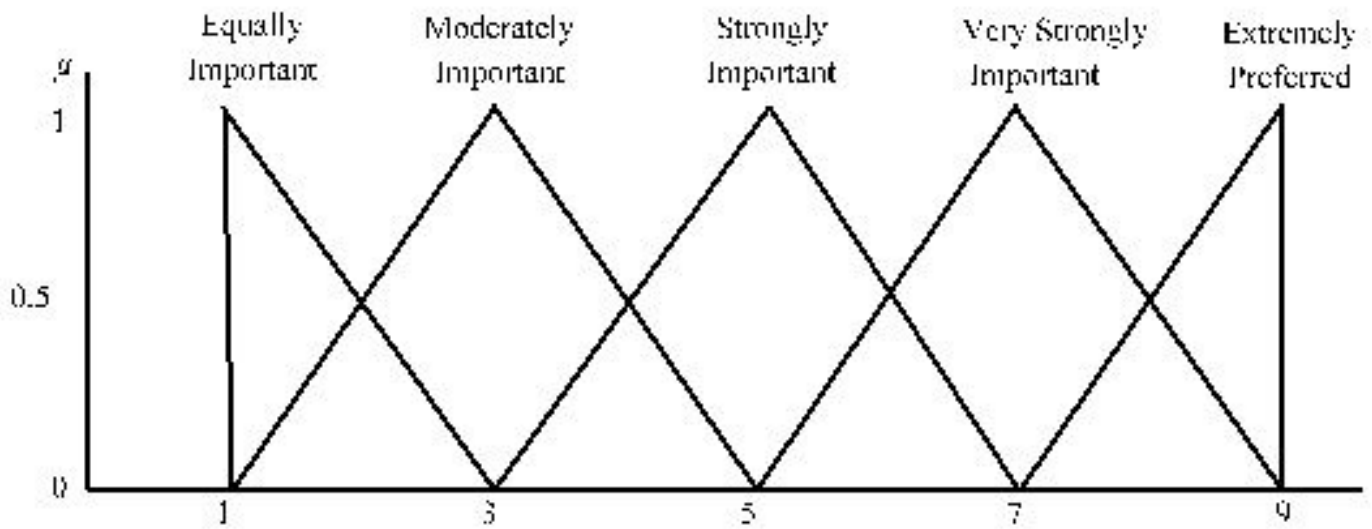

Figure 2

Linguistic variables for the importance weight of each criterion (Chang, 1996)

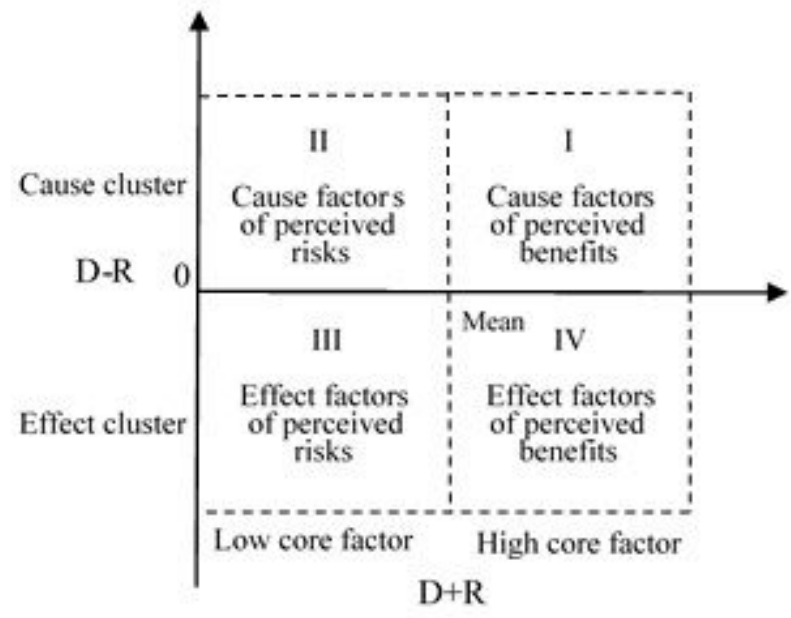

Figure 3

Causal diagram 


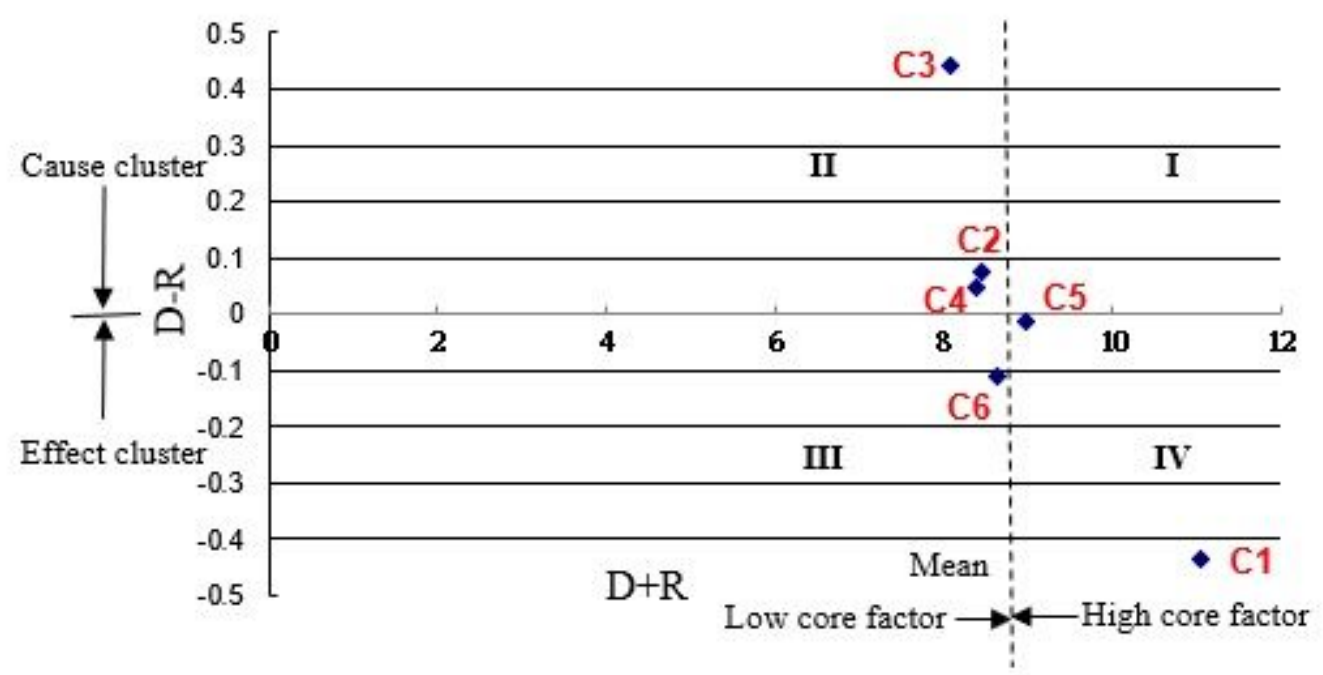

Using • symbol for evaluating criteria: Patient Care (C1), Medical Knowledge (C2), Practice-based learning and improvement (C3), Interpersonal and communication skills (C4), Professionalism (C5), and Systems-based practice (C6)

\section{Figure 4}

Causal diagram

\section{Supplementary Files}

This is a list of supplementary files associated with this preprint. Click to download.

- ACGME20210224appendix.docx 